\title{
Comparison between GOES-12 Overshooting-Top Detections, WSR-88D Radar Reflectivity, and Severe Storm Reports
}

\author{
RICHARD DWORAK \\ Cooperative Institute for Meteorological Satellite Studies, University of Wisconsin-Madison, Madison, Wisconsin \\ KRISTOPHER BEDKA \\ Science Systems and Applications, Inc., Hampton, Virginia \\ JASON BRUNNER AND WAYNE FELTZ \\ Cooperative Institute for Meteorological Satellite Studies, University of Wisconsin-Madison, Madison, Wisconsin
}

(Manuscript received 21 June 2011, in final form 29 November 2011)

\begin{abstract}
Studies have found that convective storms with overshooting-top (OT) signatures in weather satellite imagery are often associated with hazardous weather, such as heavy rainfall, tornadoes, damaging winds, and large hail. An objective satellite-based OT detection product has been developed using 11- $\mu \mathrm{m}$ infrared window (IRW) channel brightness temperatures (BTs) for the upcoming R series of the Geostationary Operational Environmental Satellite (GOES-R) Advanced Baseline Imager. In this study, this method is applied to GOES-12 IRW data and the OT detections are compared with radar data, severe storm reports, and severe weather warnings over the eastern United States. The goals of this study are to 1) improve forecaster understanding of satellite OT signatures relative to commonly available radar products, 2) assess OT detection product accuracy, and 3) evaluate the utility of an OT detection product for diagnosing hazardous convective storms. The coevolution of radar-derived products and satellite OT signatures indicates that an OT often corresponds with the highest radar echo top and reflectivity maximum aloft. Validation of OT detections relative to composite reflectivity indicates an algorithm false-alarm ratio of $16 \%$, with OTs within the coldest IRW BT range $(<200 \mathrm{~K})$ being the most accurate. A significant IRW BT minimum typically present with an OT is more often associated with heavy precipitation than a region with a spatially uniform BT. Severe weather was often associated with OT detections during the warm season (April-September) and over the southern United States. The severe weather to OT relationship increased by $15 \%$ when GOES operated in rapid-scan mode, showing the importance of high temporal resolution for observing and detecting rapidly evolving cloud-top features. Comparison of the earliest OT detection associated with a severe weather report showed that $75 \%$ of the cases occur before severe weather and that $42 \%$ of collocated severe weather reports had either an OT detected before a severe weather warning or no warning issued at all. The relationships between satellite OT signatures, severe weather, and heavy rainfall shown in this paper suggest that 1) when an OT is detected, the particular storm is likely producing heavy rainfall and/or possibly severe weather; 2) an objective OT detection product can be used to increase situational awareness and forecaster confidence that a given storm is severe; and 3) this product may be particularly useful in regions with insufficient radar coverage.
\end{abstract}

Corresponding author address: Richard Dworak, Cooperative Institute for Meteorological Satellite Studies, University of Wisconsin-Madison, 1225 West Dayton St., Madison, WI 53706. E-mail: rdworak@ssec.wisc.edu

\section{Introduction and background}

Numerous studies have demonstrated that convective storms with overshooting-top (OT) signatures in weather satellite imagery often produce hazardous weather at 
the earth's surface, such as heavy rainfall (Negri and Adler 1981), damaging winds (Heymsfield et al. 1991), large hail (Reynolds 1980), and tornadoes (Heymsfield and Blackmer 1988; Fujita 1989; Kellenbenz et al. 2007). Due to the hazardous nature of storms with OTs, objective OT and enhanced- $\mathrm{V}$ signature detection is a product requirement for the Geostationary Operational Environmental Satellite R series (GOES-R) Advanced Baseline Imager (ABI) Algorithm Working Group (AWG) program (Schmit et al. 2005; see also: http:// www.goes-r.gov/products/option2.html). The ABI will provide infrared window (IRW) imagery at $2-\mathrm{km}$ spatial resolution in 5-min intervals over the continental United States (CONUS), with a 30-s-resolution imaging capability over a $1000 \mathrm{~km} \times 1000 \mathrm{~km}$ region where significant severe weather is expected or occurring. OTs exhibit a lumpy or "cauliflower" textured appearance in visible channel imagery. OTs often appear as small clusters ( $\leq 15 \mathrm{~km}$ in diameter) of very cold IRW brightness temperatures (BTs). OTs continue to cool at a rate of $7-9 \mathrm{~K} \mathrm{~km}^{-1}$ as they ascend into the lower stratosphere, producing a significant BT contrast between the OT region and the surrounding anvil cloud (Negri 1982; Adler et al. 1983). The surrounding anvil cloud has been shown to have temperatures at or near that of the tropopause level (Adler et al. 1985).

An objective OT detection product has been developed that focuses on the attributes of OTs as depicted in GOES-12 Imager IRW imagery (Bedka et al. 2010). Clusters of pixels significantly colder than the surrounding anvil cloud with a diameter consistent with commonly observed OTs are identified through this approach. This algorithm is highly efficient since it can process a $4-\mathrm{km}$ spatial-resolution (at nadir) GOES image over the CONUS in under $30 \mathrm{~s}$, allowing for processing in real time or with large volumes of archived global geostationary and polar-orbiting satellite data.

The accuracy of this so-called IRW-texture method has been quantified relative to OT signatures depicted in National Aeronautics and Space Administration (NASA) CloudSat Cloud Profiling Radar (CPR) data and cloudresolving NWP model output (Bedka et al. 2010; Bedka et al. 2012). While these studies provide relatively consistent false-alarm rate (FAR) statistics for the OT detection product, neither utilized a large sample size of geostationary satellite imagery over the CONUS that is currently available to operational weather forecasters; thus, these FARs may not be representative of nearreal-time CONUS product output and more validation must be done.

The purpose of this paper is to expand upon previous studies examining the relationships between satellite-observed OT signatures, radar reflectivity, and reported severe weather in an effort to 1) improve forecaster understanding of OT detection output relative to commonly available radar products, 2) assess OT detection product accuracy, and 3) demonstrate the utility of an OT detection product for diagnosing hazardous convective storms over the continental United States. The volume of data used in this study far exceeds that from previous work, which had primarily relied on a limited sample size of case studies, or in the case of Bedka (2011), a relatively small severe weather event database.

\section{Data}

\section{a. GOES-12}

GOES-12 data over the CONUS east of $105^{\circ} \mathrm{W}$ were used in this study. The 10.7- $\mu \mathrm{m}$ IRW channel data from both the 15-30-min operational and 5-10-min rapidscan datasets obtained during a January 2004-December 2009 period (inclusive) were used as input into the IRWtexture OT detection algorithm. Data from 10.7- $\mu \mathrm{m}$ IRW and $0.65-\mu \mathrm{m}$ visible channels were analyzed for individual storm events to confirm the presence of OTs. The actual scan time of the GOES satellite over the CONUS is estimated to be $\sim 3 \mathrm{~min}$ after the image's time stamp. This factor is taken into account when comparing OT detections with radar reflectivity and severe weather observations. Though the spatial resolution of GOES-12 is $4 \mathrm{~km}$ at nadir, the actual resolution over the CONUS ranges from $4.7 \mathrm{~km}$ over southeast Florida to $8.9 \mathrm{~km}$ along the U.S.-Canada border in eastern Montana. The GOES data were acquired from the University of Wisconsin-Madison's Space Science and Engineering Data Center (UW-SSEC) via the Man computer Interactive Data Access System (McIDAS-X; Lazzara et al. 1999).

\section{b. WSR $-88 D$}

National Oceanic and Atmospheric Administration (NOAA) Weather Surveillance Radar-1988 Doppler (WSR-88D) radar reflectivity and derived products are used in this study to 1) show the evolution of precipitation and cloud-height structures while OT signatures are detected in geostationary satellite IRW imagery, 2) provide a radar reflectivity-based validation of the detection algorithm, and 3) show the mean relationship between the OT minimum IRW BT and the intensity of the underlying precipitation echo. For the first objective, base reflectivity and composite reflectivity are subjectively monitored for 207 individual storms over a 1-h period centered on the time of OT detection in GOES-12 IRW imagery. Composite reflectivity is defined as the maximum reflectivity at any elevation scan for a given range gate. The reflectivity and derived products for individual 
radar sites were from the 2008 warm season (AprilSeptember) and were acquired from the NOAA/National Climatic Data Center (NCDC; http://www.ncdc.noaa. gov/nexradinv/). For the second and third objectives, a 1-km spatial-resolution composite reflectivity mosaic covering the entire study domain during 2008 is objectively compared with OT detections. The composite reflectivity mosaic data were acquired from Unidata via McIDAS-X. The methodology used to accomplish these objectives will be described in the following section.

\section{c. NOAA/SPC Severe Weather Database}

Severe weather reports from the NOAA/Severe Prediction Center (SPC) Severe Weather Database (SPCSWD; http://www.spc.noaa.gov/wcm/\#data) are objectively compared with GOES-12 OT detections during the 2004-09 study period. The data files contain the date, time, and latitude-longitude coordinates of tornado, large hail ( $\geq 0.75 \mathrm{in}$.), and severe wind reports $\left(\geq 50 \mathrm{kt}\right.$, where $\left.1 \mathrm{kt}=0.514 \mathrm{~m} \mathrm{~s}^{-1}\right)$ in addition to the tornado Fujita scale (F scale) rating, hail diameter, or wind speed of the severe weather event. These reports are collected by NOAA/National Weather Service (NWS) field offices across the United States and are carefully reviewed by SPC and NCDC to ensure their quality and validity.

\section{d. Severe weather warning database}

All severe thunderstorm and tornado warnings issued by the NWS during the 2004-09 study period were acquired from the Iowa State University Department of Agronomy Archived NWS Watch/Warning database (http://mesonet.agron.iastate.edu/request/gis/watchwarn. phtml). The data were provided in Shapefile Database format, which included information such as the date-time of warning initiation and expiration, latitude and longitude boundaries of the warning, and warning type.

\section{Methodology}

\section{a. IRW-texture OT detection method}

Bedka et al. (2010) describe the IRW-texture OT detection algorithm in full detail, but a short summary is provided here for context. The algorithm was designed to accurately identify pixels penetrating through the tropopause region and its output was not expected to specifically be a "severe weather detection" product. The algorithm is formulated around the premise that OTs appear as small clusters of pixels ( $\leq 15-\mathrm{km}$ diameter) that are significantly colder than the surrounding anvil cloud. Relative BT minima that are $\leq 215 \mathrm{~K}$ are first identified. These pixels are then compared to the NWP tropopause temperature to verify that the pixels are indeed cloud tops "overshooting" through the tropopause region. Checks are then performed to ensure that no minima are located within $15 \mathrm{~km}$ of each other so that portions of the same OT are not classified as two independent tops. The IRW BT of the anvil cloud surrounding the potential OT is then sampled at $\sim 8$ - $\mathrm{km}$ radius in 16 directions. The surrounding anvil pixels must have an IRW temperature at or colder than $225 \mathrm{~K}$ to be included in the mean computation. At least five valid anvil pixels must be present. The 5-of-16-pixel criterion is imposed to ensure that the anvil is of relatively large horizontal extent but allows an anvil to occupy as small as a $90^{\circ}$ quadrant, which might be the case when strong jet-level winds are present.

A pixel is classified as an overshooting top if it is $\geq 6.5 \mathrm{~K}$ colder than the mean BT of the surrounding anvil cloud. The difference between the OT minimum and mean anvil BTs is referred to as the overshooting magnitude in this paper, where a larger difference would likely imply a more significant penetration above the anvil cloud. If a pixel does not pass the anvil extent and/ or magnitude tests, it is referred to as a non-OT cold pixel, which indicates that the anvil cloud is small or the pixel is within a region of relatively uniform IRW BTs. These will be used in portions of the forthcoming analysis and may have an impact on the precipitation structure near the pixel.

The 215-K OT BT, 225-K anvil cloud BT, and 6.5-K overshooting magnitude thresholds described above were selected based on detailed analysis of 450 warm season OT events in the Moderate Resolution Imaging Spectroradiometer (MODIS) and the Advanced Very High Resolution Radiometer (AVHRR) imagery. Testing was done with alternative thresholds including a 220-K OT BT, 230-K anvil cloud BT, and 4.5-K OT magnitude during the GOES-R AWG development process and it was determined that these thresholds provided detection accuracy that would not meet the $25 \%$ maximum FAR criterion mandated by the AWG program. IRW BT patterns can become especially complex in cold season midlatitude cyclones. Localized BT minima colder than the NWP tropopause may look like OTs within the IRWtexture method but are obviously not OTs based on inspection of visible channel imagery. A lowering of the required OT BT threshold may improve detection of weak OT signals at the expense of producing a significant number of false detections.

For statistical comparisons against WSR-88D and the SPCSWD, the locations of OT detections are corrected for parallax assuming a constant cloud-top height of $14 \mathrm{~km}$ to better match the actual positions of these features relative to the earth's surface. Inclusion of a pixel-scale cloud-top height retrieval dataset was not possible for this study and 
a simple comparison of an IR BT to an NWP or radiosonde temperature profile can be problematic. It is understood that the peak OT height is not constant across all events, so there will be some error in parallax correction if the peak height differs significantly from $14 \mathrm{~km}$. For example, at $49^{\circ} \mathrm{N}, 105^{\circ} \mathrm{W}$, near the northwest corner of the domain, a peak height of $16 \mathrm{~km}$ would require an additional 3.9-km correction and an additional 8-km correction would be required for an 18-km peak height. Non-parallaxcorrected OT detections are shown when overlaid atop satellite imagery.

\section{b. Comparison of OT detections with WSR-88D datasets}

The relationships between OT detections and WSR-88D reflectivity and derived products were both subjectively and objectively analyzed. For the subjective analysis, the base and composite reflectivity for 207 daytime OTproducing storms were monitored over a 1 -h period centered on the time of a GOES OT detection. The 207 events occurred throughout the study domain during the 2008 warm season. Daytime storms were selected so that visible imagery could be used to verify the accuracy of the GOES OT detections. All 207 of the OT detections were associated with the cauliflower-like texture characteristics of OTs in visible channel imagery. This ensures that the radar evolution documented in this paper is associated with actual OT events. The base and composite reflectivity were recorded for all radar scans within this 1-h time window. The time of the first occurrence of an OT detection is used as the midpoint of the 1-h period. The reflectivity time series for each of the storms were averaged together to show the radar evolution for verified OT-producing storms.

Three storms were also analyzed in greater detail to show the evolution of the radar-derived fields when OTs were observed. These storms occurred on 16 July 2008 over central Wisconsin. Two were associated with damaging winds and/or hail: the first occurring near Beaver Dam, Wisconsin, and the second near La Valle, Wisconsin. The maximum reflectivity in the OT region at multiple elevation angles was recorded. The echo top (ET) is analyzed to show the relationship between peak radar echo height and the time of OT detection. Vertically integrated liquid (VIL) is analyzed since this field provides an inference of the total precipitation mass within a vertical column in the storm and convective vigor. Similar to the analysis of the 207 storms, each product is analyzed relative to the time of the first OT detection.

For the objective component of the radar analysis, 25921 (1854) warm (cold) season OT detections and 76158 (22 792) warm (cold) season non-OT cold pixels during 2008 over the study domain were objectively compared with the WSR-88D composite reflectivity mosaic to find the maximum reflectivity within $5 \mathrm{~km}$ and 3 min of a parallax-corrected OT location. The purpose of this analysis is to document the reflectivity characteristics for storms with varying minimum OT IRW BT, which can help one to infer the underlying radar echo near an OT where radar data are inadequate or unavailable. We assume that an OT should be associated with a composite reflectivity of greater than $30 \mathrm{dBZ}$, a value typically associated with newly developing convective storms. The OTs with a composite reflectivity below $30 \mathrm{dBZ}$ are considered false OT detections; thus, this analysis also serves to validate the OT detection product. The authors do not have the means to identify radar outages within the Unidata dataset, so an OT detection in a region without radar data will be a false alarm. Non-OT pixels are also compared with composite reflectivity in the same manner as OT pixels to show differences in reflectivity characteristics near these pixels.

\section{c. Comparison of OT detections with the SPCSWD}

Severe weather reports from the SPCSWD were compared with OT detections to determine the frequency of OT detections near severe weather and the severe weather forecast lead time that can be offered by this satellite-derived product. Included in this analysis are 81559 large hail, 76183 damaging wind, and 7750 tornado reports over the study domain from 2004 through 2009. A total of 561250 OT detections were produced during this time frame using all operational and rapid-scan (when available) GOES-12 imagery from the UW-SSEC archive.

Analysis of the severe weather frequency near any OT detection cannot be performed because severe weather is often underreported, especially in sparsely populated areas or over bodies of water (Dobur 2005; Cecil 2009). While we would not expect every OT-producing storm to be severe, such a comparison would yield unrealistically low OT-severe weather relationships, giving one the false impression that the OT product is not useful for severe weather nowcasting.

To determine the frequency of OT detections near severe weather reports, any OT detection that is within $\pm 30 \mathrm{~min}$ and either 30 or $60 \mathrm{~km}$ of a severe weather report is considered a match. These somewhat broad time and space windows take into account 1) maximum storm movement of $60 \mathrm{~km} \mathrm{~h}^{-1}$ and the 5-30-min interval between GOES images, 2) the fact that an OT detection could precede or possibly follow severe weather at the surface, 3) tilt of the updraft region with height so the severe weather may not be perfectly collocated with the OT detection location, 4) errors in the timing and location of reported severe weather events, 


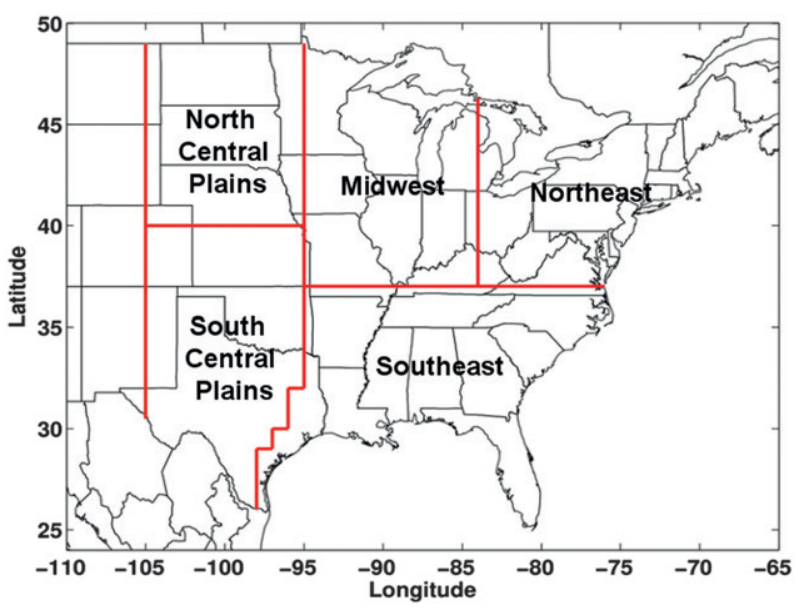

FIG. 1. A map showing the five regions examined in this study.

5) inadequate parallax correction, and 6) satellite pixel navigation error. The $60-\mathrm{km}$ threshold is included to evaluate the sensitivity of the statistics to the choice of match criteria. The time match criterion is not varied because it is likely that other nearby severe storms could move into the search region and influence the statistics. A severe weather event is not compared with OT detections if two or fewer GOES scans occur within the \pm 30 -min time window. This is done to prevent these scenarios from biasing the statistical relationships. An example of this scenario is a severe report at 1805 UTC when the only two GOES scans at 1745 and 1815 UTC are available for comparison. Results are separated by severe weather type, geographic region (see Fig. 1), and cold (October-March) versus warm (April-September) season. The time difference between an OT detection and a severe weather report is also noted to investigate the severe weather forecast lead time and situational awareness that may be offered by this product.

One should not expect OTs to be detected near $100 \%$ of severe weather events given the coarse spatial-temporal resolutions of current GOES data relative to the characteristic size-lifetime of an OT. The authors have compared OT signatures within 1-2-km MODIS and AVHRR imagery with 5-9-km GOES-12 imagery for 125 enhanced- $\mathrm{V}$ producing severe storm cases (Brunner et al. 2007) and have found that the OT IRW BT is $12 \mathrm{~K}$ colder on average in the higher spatial resolution MODIS-AVHRR data. Thus, the OT signature in GOES will be far less pronounced relative to the surrounding anvil and harder to detect using IR-based methods. Examination of 1-min GOES Super Rapid Scan observations of deep convection by the authors of this paper (see the following for an example: http:// cimss.ssec.wisc.edu/goes/blog/wp-content/uploads/2010/ 09/100921_g15_srso_vis_overshoots_anim.gif) indicates that the typical lifetime of an OT is less than $5 \mathrm{~min}$. Therefore, an OT can form 1 min after a GOES scan and the parent thunderstorm produces severe weather possibly 0-13 min later. Given the challenges described here and the 4-times and 3-times improvements in future GOES-R ABI spatial and temporal resolutions (respectively), the authors believe that the relationships shown in this paper represent a low-end estimate of this product's future capability for identifying severe storms in the GOES-R ABI era.

\section{d. Comparison of OT detections with severe weather warnings}

The objective of this analysis is to assess the time differential between GOES OT detections and severe weather warnings to demonstrate that an OT signature can improve situational awareness of a storm's potential severity especially in the absence of radar coverage. OT detections occurring within a \pm 30 -min and $30-\mathrm{km}$ window of an SPCSWD report are examined here. If the same severe weather report had multiple OTs associated with it, only the earliest collocation was used in the analysis. The first step in the process looks for severe reports within the time frame and geographic boundaries of the warning. If no severe report is found within the warned region-time frame, a region $10 \mathrm{~km}$ outside the warned region but within the time frame is searched. Even though these cases would technically not be warned severe weather events, this approach incorporates the minority of events where erratic storm motions or gust fronts produce severe reports in the vicinity of, but outside of, the warned area. The time difference between the issue time of the warning and the severe report is noted in addition to the time difference between the OT detection and severe report. Since the OT-severe weather temporal collocation criterion is limited to $30 \mathrm{~min}$, only severe weather warnings with a maximum duration of $30 \mathrm{~min}$ are included in this analysis, so an unbiased comparison can be made between the OT and warning. A comparison was also done for all severe weather warning durations to place the 30-min warning duration results into context.

\section{Results}

\section{a. Case study of a severe weather event over central Wisconsin}

A large mesoscale convective system moved across Wisconsin on 16 July 2008, producing numerous incidents of severe wind and hail. OTs were detected near reported severe weather across Wisconsin and other regions of the United States, but many OTs such as those over the sparsely populated elevated terrain of New Mexico and 

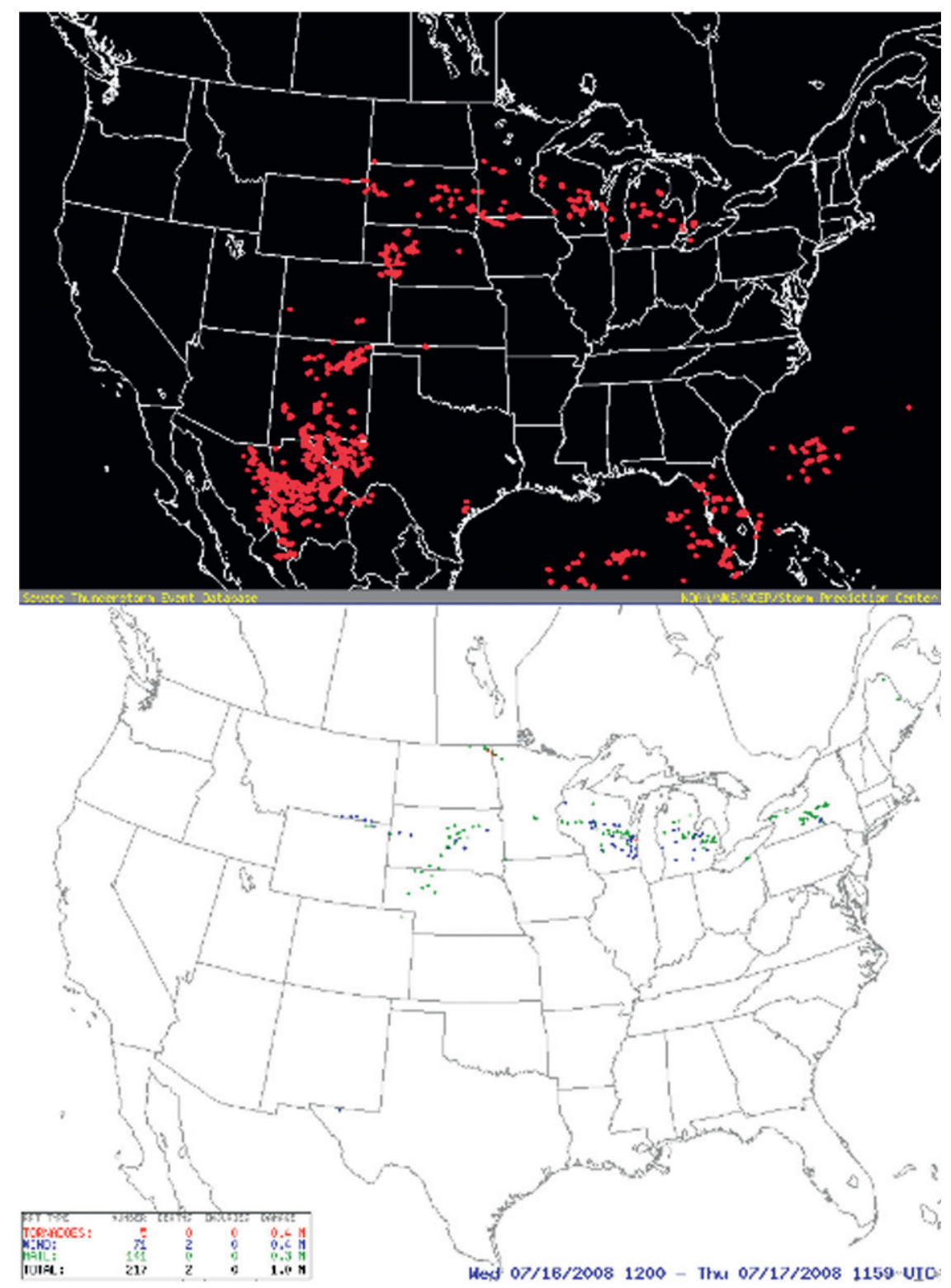

FIG. 2. (top) A map of GOES-12 OT detections between 1200 UTC 16 Jul and 1159 UTC 17 Jul 2008. (bottom) Severe weather reports from the SPC over the same time period.

western Texas were not located near any severe reports (Fig. 2). Three OT-producing storms over central Wisconsin are the focus of this discussion. Severe wind was reported near Beaver Dam at 2035 and 2051 UTC and severe wind and hail was reported near La Valle at 2115 and 2120 UTC.

An OT was detected within the first storm of interest near Portage, Wisconsin, at 2015 UTC (Fig. 3, left). The NWS issued a severe thunderstorm warning at 2021 UTC for this storm. The IRW imagery shows the focused BT minimum that is detected by the objective OT detection algorithm. Comparison of the OT detection, the IRW BT field, and WSR-88D composite reflectivity indicates that a relative reflectivity maximum is associated with the OT and BT minimum, but there is not a monotonic relationship between reflectivity and IRW $\mathrm{BT}$, in that greater reflectivities are present in non-OT regions. High reflectivity with relatively low IRW BTs is present near La Valle, whereas the opposite is occurring in the stratiform precipitation region over the northeast portion of the domain. The echo top near the OT is approaching $50 \mathrm{kft}$ (15.2 km; Fig. 4), though Fig. 3 does not portray this well since the WSR-88D fields are remapped to the GOES visible resolution $(\sim 1.3 \mathrm{~km}$ over 

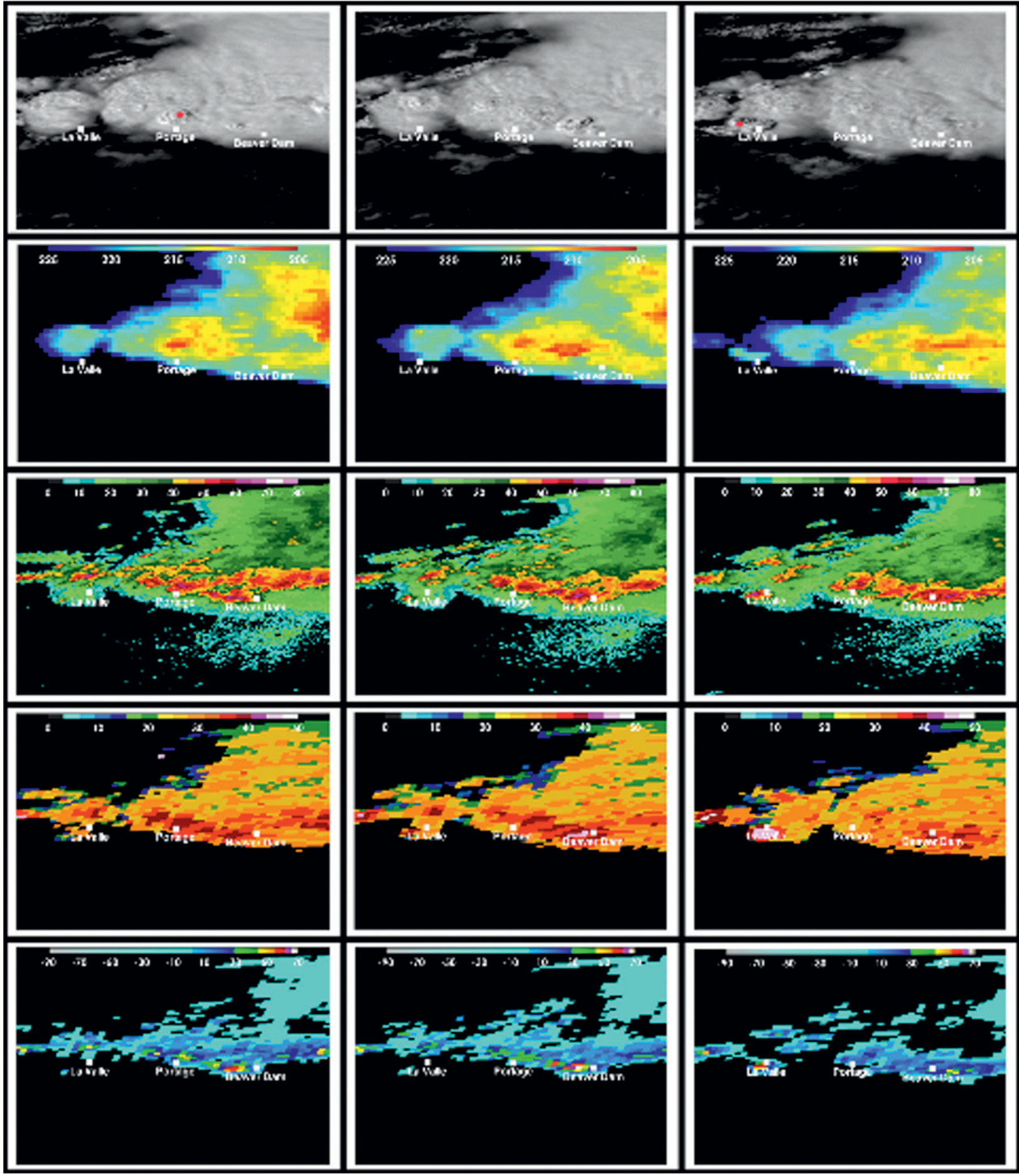

FIG. 3. (top) GOES-12 visible channel imagery with objective OT detections (red dots); (second row) GOES-12 IRW imagery; (third row) Milwaukee, WI (KMKX), WSR-88D composite reflectivity; (fourth row) KMKX WSR-88D echo-top product; and (bottom) KMKX WSR-88D VIL at or near (left) 2015, (center) 2025, and (right) 2040 UTC16 Jul 2008. These three times were selected to show the satellite and radar-derived fields when OTs were either objectively detected (2015 and 2040 UTC) or observed in visible imagery (2025 UTC) Satellite imagery and the OT detections are not parallax corrected for these examples. Radar-derived fields are mapped to the satellite image projection and resolution. The locations of La Valle, Portage, and Beaver Dam are shown. 


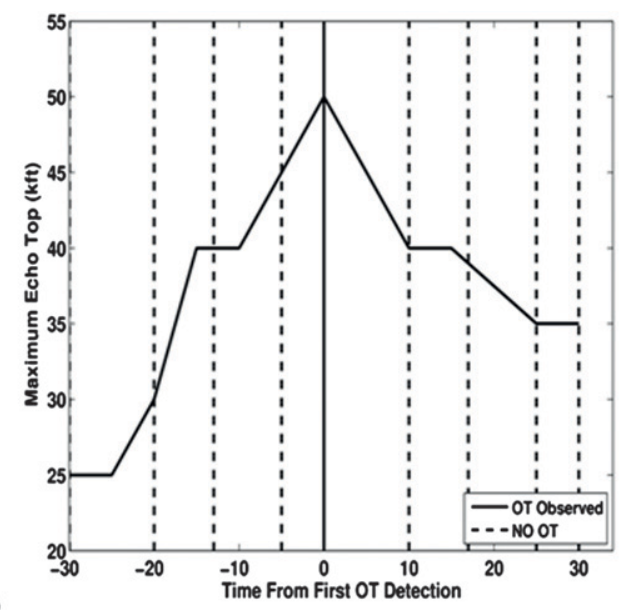

a)

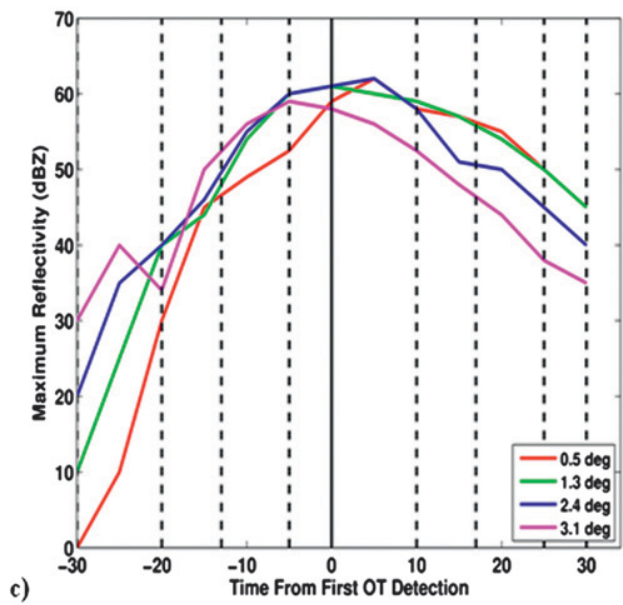

b)

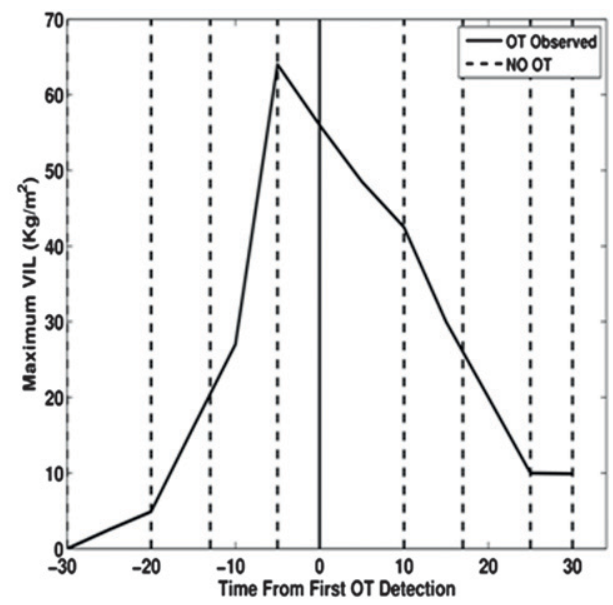

FIG. 4. Time series of WSR-88D reflectivity derived within a \pm 30 -min time period from an OT detection within the Portage storm: (a) echo top (kft), (b) VIL $\left(\mathrm{kg} \mathrm{m}^{-2}\right)$, and $(\mathrm{c})$ reflectivities $(\mathrm{dBZ})$ at four elevation angles $\left(0.5^{\circ}, 1.5^{\circ}, 2.4^{\circ}\right.$, and $\left.3.1^{\circ}\right)$. The dashed vertical lines are GOES-12 observation times when no OT was detected and the solid vertical line was the time when an OT was detected. this region) and geostationary satellite viewing projection. Relative maxima of VIL are associated with the Portage and emerging Beaver Dam OTs, indicating strong vertical motions and significant precipitation mass within the vertical columns near the OTs. No severe weather was reported near this OT and analysis of subsequent images shows that it soon dissipated without reforming, but the parent storm cell continued to produce heavy rain. The maximum reflectivity at $3.1^{\circ}$ elevation occurred approximately 5 min before OT detection, caused by lofting of precipitation within the storm updraft. The reflectivity maximum descended to lower levels soon after OT detection, consistent with the satellite observations of the OT collapse.

An OT became much more pronounced in the visible channel imagery at 2025 UTC near Beaver Dam (Fig. 3, middle). The NWS issued a severe thunderstorm warning for this storm at 2011 UTC. This OT was not detected because its magnitude was only $6 \mathrm{~K}$, which was slightly below the $6.5-\mathrm{K}$ threshold required by the GOES algorithm. While the minimum IRW BT for this OT is $206.9 \mathrm{~K}$, the region of relatively cold BTs $(<213 \mathrm{~K})$ is more expansive than the Portage OT, thereby skewing the anvil mean BT within the algorithm to a colder value. As observed in the Portage event, maximum echo-top height and VIL occurred in conjunction with the time of OT detection (Fig. 5). The reflectivity evolution also showed a similar pattern with significant reflectivity echoes aloft near the time of OT detection that soon descended to $0.5^{\circ}$-elevation level.

An OT was also detected within a rapidly developing storm near La Valle at 2040 UTC (Fig. 3, right). The NWS issued a severe thunderstorm warning for this storm at 2047 UTC. The area of IRW BT colder than $225 \mathrm{~K}$ is quite small for this storm, but enough anvil pixels were present to derive a mean anvil BT within the IRW-texture algorithm. A $\sim 55 \mathrm{kft}(16.7 \mathrm{~km})$ echo top and $\sim 73 \mathrm{~kg} \mathrm{~m}^{-2}$ VIL maximum is evident at the time of 
a)
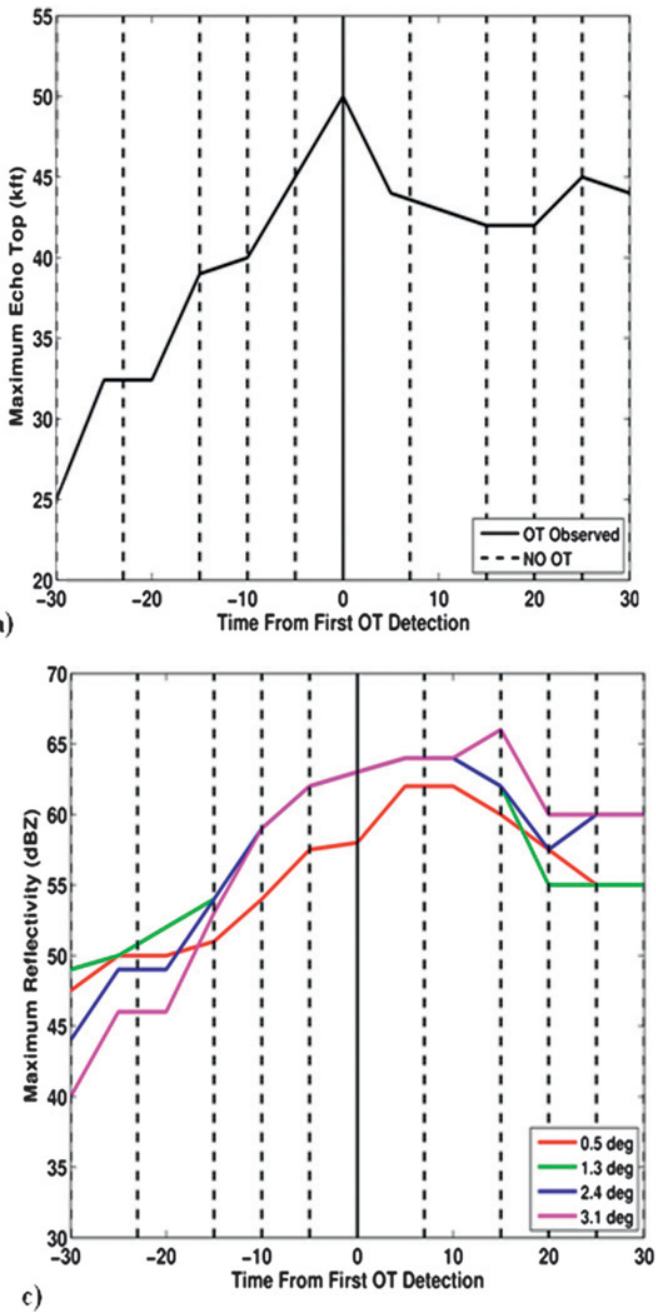

OT detection with a general lowering in these parameters afterward (Fig. 6). The time evolution of reflectivity shows similar patterns to the other OT-producing storms discussed above, though relatively high values persist at all elevation scans after OT detection. This may be related to the fact that this storm is newly developing and may have produced another OT $\sim(20-30)$ min later in association with a subtle increase in echo top and VIL. Unfortunately, GOES-12 was scanning the full disk at 2045 UTC, which causes the 30-min gap in images between 2045 and 2115 UTC. Severe weather was reported at 2115 and 2120 UTC at a time with no OT detection, descending echo top, and lower VIL values. Though this cannot be effectively verified with the datasets available to the authors, it is possible that hail was present aloft prior to the report, which later fell to the surface as the echo top lowered and the updraft weakened. The GOES$\mathrm{R}$ ABI will provide routine 5-min data over CONUS, eliminating the 30-min full-disk scan gap and allowing forecasters to better monitor severe convection.

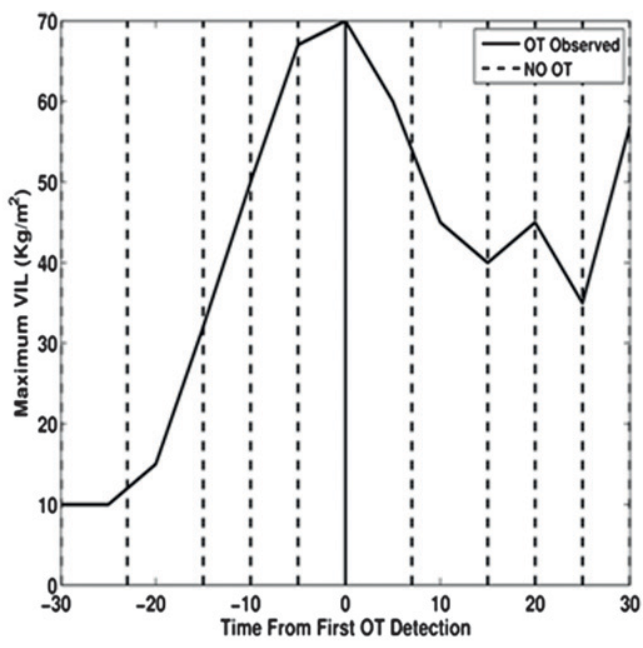

b)

FIG. 5. As in Fig. 4, but for the Beaver Dam storm. The solid vertical line in the middle of these plots indicates the time that the OT was subjectively detected by a human analyst, not the OT detection algorithm.

\section{b. Statistical overshooting top and radar reflectivity relationships}

Composites and base reflectivities for confirmed OTproducing storms were analyzed surrounding the time of 207 OT signatures. A linear increase in both composite and base reflectivity occurred within the 30 -min period prior to OT detection (Fig. 7). Reflectivity maximized aloft at the time of or shortly before OT detection, whereas base reflectivity maximized at the time of or shortly after OT detection. This suggests that hydrometeors are lofted by the strong overshooting updraft that later descends to the surface as the updraft weakens (Srivastava 1987; Roberts and Wilson 1989). These results agree with the findings of Adler et al. (1983), who showed that peak radar echo intensity generally occurs near the time when overshooting is occurring.

OTs detected during both the 2008 warm and cold seasons over the study domain were objectively compared with the WSR-88D composite reflectivity mosaic 


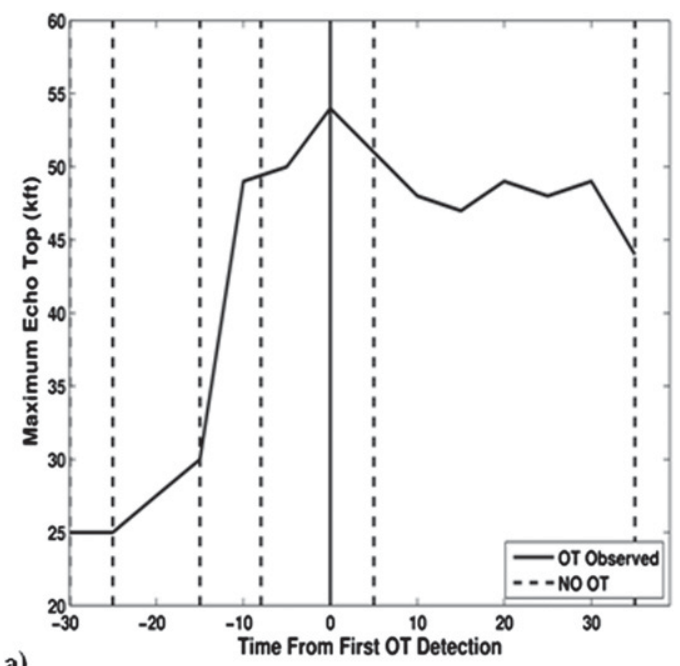

a)

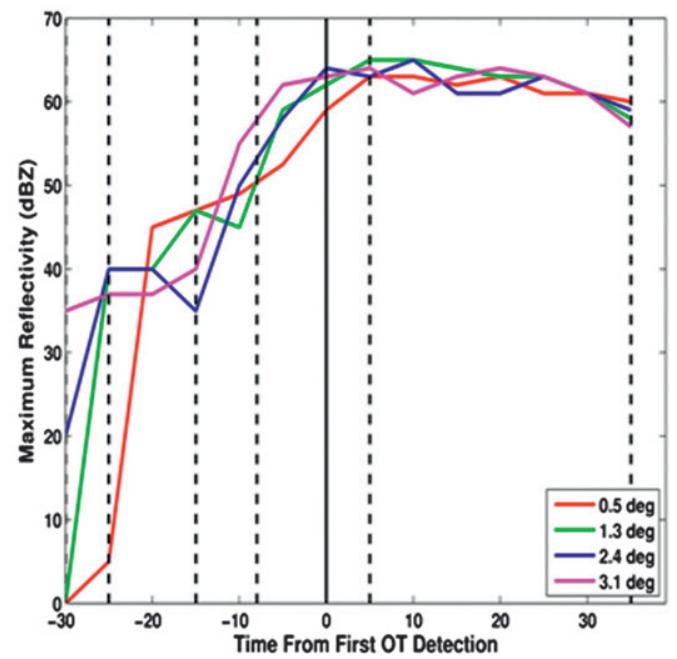

c)

to provide a radar reflectivity-based validation of the detection algorithm and to show the mean relationship between OT minimum IRW BT and the intensity of the underlying precipitation echo. The FAR for warm season OT detections is $16 \%$ under the assumption that OTs should be associated with at least a 30-dBZ composite reflectivity (Fig. 8 ). The FAR ranges from $6 \%$ to $24 \%$ with the lowest value associated with IRW BTs $\leq$ $200 \mathrm{~K}$. The cold season results show a similar correlation between IRW BT and FAR, but the FAR for IRW BT between 210 and $215 \mathrm{~K}$ is significantly higher. The number of OTs with BT in this range is significantly higher than those in colder BT intervals; thus, the frequency for the combined curve is lowered, with a $31 \%$ FAR value.

A significant IRW BT minimum that is spatially confined is more often associated with heavy precipitation than a region with a spatially uniform BT. A warm season

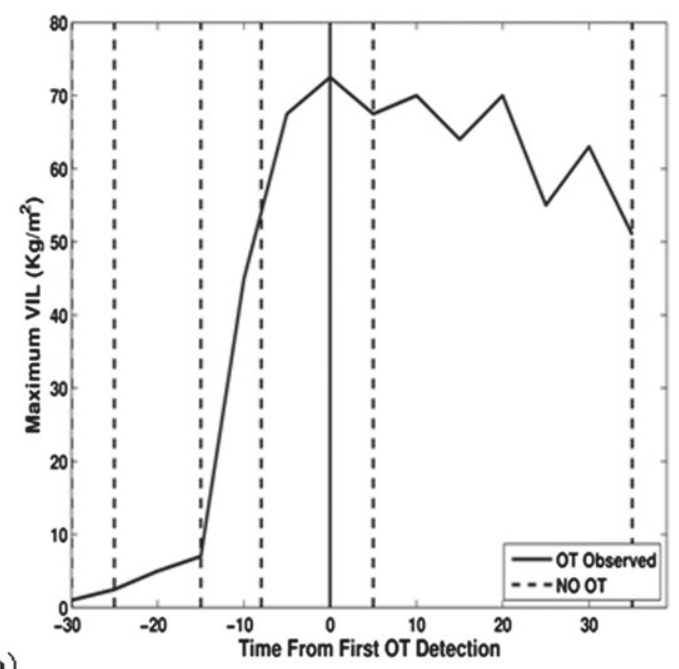

FIG. 6. As in Figs. 4 and 5, but for the La Valle storm. The time interval extends to $35 \mathrm{~min}$ after the OT detection to account for the 30-min gap in GOES images.

comparison of the solid and dashed black curves in Fig. 8 illustrates that a pixel with an IRW BT of at least $6.5 \mathrm{~K}$ colder than the surrounding anvil is $40 \%(12 \%)$ more likely to be associated with a $\geq 45$ - (60) dBZ echo than a pixel with a lesser OT-anvil BT difference (i.e., a nonOT cold pixel). The non-OT cold pixel curves asymptotically to a $\geq 60-\mathrm{dB} Z$ frequency of $\sim 5 \%$ regardless of IRW BT, but there is still a clear separation between the OT and non-OT curves. Cold season comparisons show similar results, but OTs were associated with lower reflectivity values, which may be due to lower total precipitable water values present during the cold season that serve to reduce the overall rainfall intensity.

In the absence of reliable radar information, a forecaster can identify regions of heavy precipitation through the detection of significant IRW BT minima via OT detections from the IRW-texture algorithm. The results suggest that a simple threshold of minimum IRW BT 


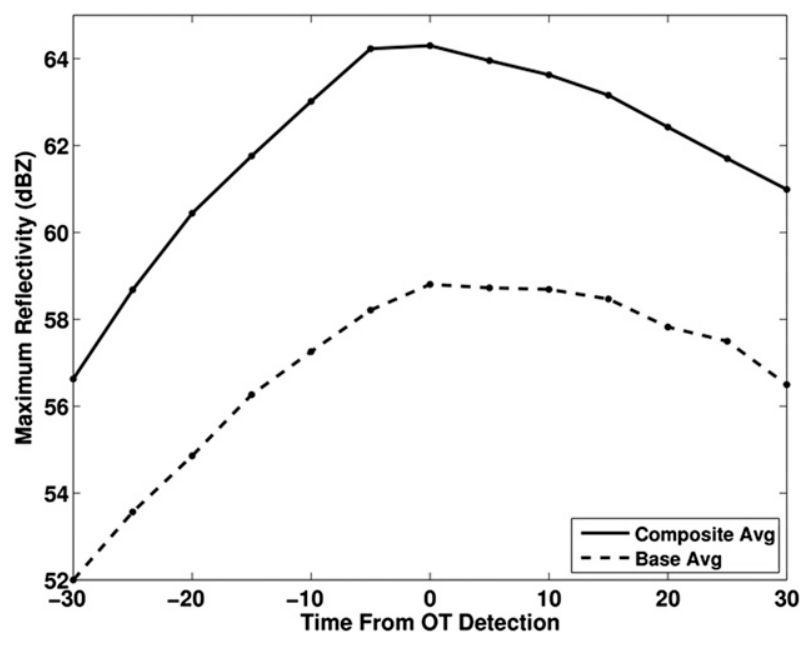

FIG. 7. The mean time evolution of the mean base and composite reflectivity within $\pm 30 \mathrm{~min}$ of the 207 confirmed OT detections.

within a storm is insufficient for identifying the occurrence of heavy precipitation as many pixels in uniform BT regions are associated with nonprecipitating cirrus anvil cloud or lighter stratiform precipitation, as seen in the Wisconsin case study.

\section{c. Comparison between SPC severe weather reports and $O T$ detections}

This analysis will focus on documenting the frequency of OT detections near confirmed severe weather events. An OT detected within $30 \mathrm{~min}$ and 30 or $60 \mathrm{~km}$ of a severe weather event is considered a match. The increase in spatial match criteria from 30 to $60 \mathrm{~km}$ increases the match frequency by $10 \%-13 \%$ (depending on season; Table 1), which suggests that either 1) OTs from other nearby storms are being inadvertently considered matches or 2) a combination of the six sources of error described in section $3 \mathrm{c}$ can cause the OT detection to be farther from the severe weather event than one might expect.

OTs were detected near $42 \%-55 \%$ of $2004-09$ warm season severe weather events, depending on match radius (Table 1). The $30-\mathrm{km}$ match statistics are slightly lower than in Bedka's (2011) study over Europe; however, OTs were detected near tornadic storms $32 \%$ more often over the United States. This difference could be related to the fact that large low-level wind shear is much more common than strong convective available potential energy (CAPE) over the European domain (Brooks et al. 2003; Bedka 2011). Therefore, tornadic storms associated with weaker updrafts relative to storms that produce severe hail-winds, resulting in a less prominent or possibly nonexistent OT signature in IRW BT imagery. In addition, the European study may have suffered from a small sample size of tornadic storm events within the European Severe Weather Database.
The OTs were detected near $22 \%-32 \%$ of cold season severe weather events, which is a significant decrease relative to the warm season results (Table 1). A significant number of potential OTs can go undetected due to the use of a fixed temperature threshold. The $215-\mathrm{K}$ isotherm drops farther south into the southeast and southern plains regions during the winter months, inhibiting the detection of overshooting convection over a greater portion of the study domain. It is possible that weaker instability during the cold season results in reduced updraft strength and thus a less prominent OT signature in IRW imagery. OTs were found most often near tornadic storms during the cold season, suggesting that storms with extremely strong updrafts and cold cloud tops are often tornadic during the cold season in contrast with the warm season where there is no clear bias toward a specific severe weather type.

Significant differences are evident when the comparisons are separated by geographic regions. The greatest percentage of severe weather-OT collocations were found over the south-central plains, while the lowest percentages of collocations were over the northeast U.S. region during both seasons (Table 2). Overall, the southern tier regions featured a greater collocation frequency than did the northern tier. However, when a warm season OT is detected over the northeast and north-central plains regions, it is more likely to be severe (not shown). Reasons for these differences may be related to the IRWtexture algorithm methodology. Hoinka (1999) shows that the $215-\mathrm{K}$ isotherm of the mean tropopause temperature during summer months is nearly zonal and cuts across the state of Pennsylvania, through the Great Lakes region, and into South Dakota. For regions north of this isotherm, the mean tropopause temperature is warmer than $215 \mathrm{~K}$, which is the maximum temperature currently allowed within the IRW-texture algorithm.

The severe weather-OT relationship is impacted significantly by the number of GOES scans that occur within the 1-h collocation time period. Figure 9 shows that the frequency of OT detection within $30 \mathrm{~km}$ of a severe report linearly increases from $33 \%$ to $48 \%$ when the number of available GOES scans increases from three to nine. This result may seem like common sense to some, but one must remember that a single OT often exists for less than $5 \mathrm{~min}$. When nine observations are collected in $1 \mathrm{~h}$, there is a higher likelihood that an OT is actually observed with a significant magnitude such that it can be detected in 5-9-km imagery. When only four observations are collected in typical 15-min operations, it is highly likely that an OT may not be present or will be in the intensification or decay stage, making it harder to detect. These results offer a preview of the severe weather detection capability that will be available in the GOES-R era. 

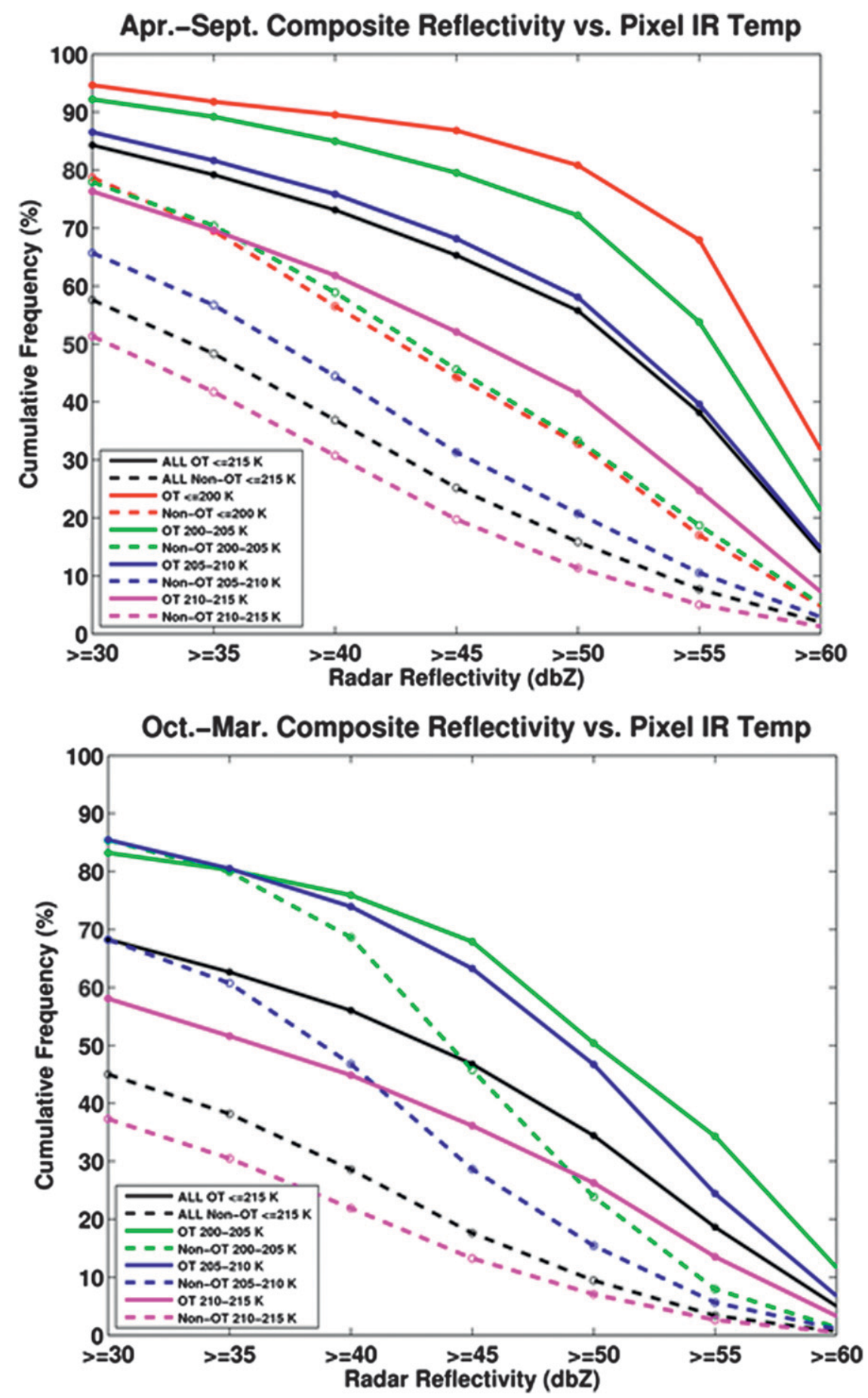

FIG. 8. A cumulative frequency diagram showing the percentage of OT detections and nonOT cold pixels during the (top) warm and (bottom) cold seasons with a composite reflectivity greater than values shown along the $x$ axis.

d. Comparison of OT detections with severe weather warnings

For matching severe weather-OT events, the time difference between the OT detection and severe weather report is derived to evaluate the potential of the OT product to provide increased situational awareness and lead time in nowcasting severe weather (Fig. 10). In situations where multiple OTs were matched with a severe report, the time of the first OT detection is used for this 
TABLE 1. The frequency of OT detections near severe weather reports during the 2004-09 warm and cold seasons. Note that any severe weather report occurring when two or fewer GOES observations were collected within $\pm 30 \mathrm{~min}$ from the report are excluded from this comparison.

\begin{tabular}{|c|c|c|}
\hline \multicolumn{3}{|c|}{ 2004-09 warm seasons } \\
\hline $\begin{array}{c}\text { Severe } \\
\text { weather type }\end{array}$ & $\begin{array}{l}\text { No. of severe } \\
\text { weather } \\
\text { occurrences }\end{array}$ & $\begin{array}{c}\text { OT match } \\
\text { percentage at a } 30-\mathrm{km} \\
(60 \mathrm{~km}) \text { radius }(\%)\end{array}$ \\
\hline Tornado & 4684 & $45.9(56.2)$ \\
\hline Severe wind & 52743 & $43.0(58.4)$ \\
\hline Large hail & 56114 & $40.8(51.3)$ \\
\hline Any type & 113541 & $42.0(54.8)$ \\
\hline \multicolumn{3}{|c|}{ 2004-09 cold seasons } \\
\hline $\begin{array}{c}\text { Severe } \\
\text { weather type }\end{array}$ & $\begin{array}{c}\text { No. of severe } \\
\text { weather } \\
\text { occurrences }\end{array}$ & $\begin{array}{c}\text { OT match } \\
\text { percentage at a } 30-\mathrm{km} \\
(60 \mathrm{~km}) \text { radius }(\%)\end{array}$ \\
\hline Tornado & 1436 & $33.2(43.5)$ \\
\hline Severe wind & 6673 & $16.4(25.9)$ \\
\hline Large hail & 7353 & $24.7(34.5)$ \\
\hline Any type & 15462 & $21.9(31.6)$ \\
\hline
\end{tabular}

comparison. The time difference between the issuance of an NWS severe weather warning and severe report is also derived. This analysis indicates that an OT was detected before the severe report for $75 \%$ of the cases, with the greatest number of OTs detected 25-30 min in advance. For comparison, Adler et al. (1985) found a median time of severe event occurrence for four cases was $20 \mathrm{~min}$ after OT formation. When severe weather warnings with a duration of $30 \mathrm{~min}$ or less are evaluated, the most frequent warning lead time was $0-5 \mathrm{~min}$ and mean warning lead time was $7.7 \mathrm{~min}$. OTs were detected $10.8 \mathrm{~min}$ ahead of the severe report on average. One-third of the cases had an OT detection before a warning was issued and 9\% of the cases were unwarned if severe weather warnings of any duration are considered. Of the severe warnings, $28 \%$ offered a lead time greater than $30 \mathrm{~min}$ but this cannot be directly compared to the OT results since the OTs were matched with severe weather with a time window of $30 \mathrm{~min}$. In summary, these results suggest that the OT detection product can improve situational awareness of a storm's possible severity, especially in the absence of radar data, giving a forecaster increased confidence that severe weather will occur if signatures of severe weather are evident on radar and one or more OTs are detected.

The lead-time results for severe wind and hail were very similar (not shown), but the tornado results differ, with OTs detected more frequently $25-30 \mathrm{~min}$ ahead of a tornado observation relative to the results for all severe types (the majority are severe wind and hail). This could point to a physical link between the OT collapse prior to tornado formation, as observed by Fujita et al. (1976) and Lemon et al. (1978), and modeled by DaviesJones (2008). This is also consistent with the theory that the total lightning decreases preceding tornadic activity (Goodman et al. 2005). The severe weather warning lead-time curve does not show any difference between tornados and other severe types. These relationships can be explored in greater detail when the algorithm is applied to 30-s- to 5-min-resolution GOES-R ABI data in conjunction with GOES-R Geostationary Lightning Mapper data as rapid fluctuations in deep convective cloud-top structure will be better observed.

\section{Summary and future work}

This paper provides detailed comparisons between satellite-based overshooting-top detections and WSR-88D

TABLE 2. The frequency (\%) of OT detections near severe weather reports for the 2004-09 warm and cold seasons, separated by geographic region. Results correspond to a $30-\mathrm{km}$ match radius.

\begin{tabular}{|c|c|c|c|c|c|}
\hline \multicolumn{6}{|c|}{ 2004-09 warm seasons } \\
\hline Severe weather type & Northeast & Southeast & Midwest & $\begin{array}{l}\text { South-central } \\
\text { plains }\end{array}$ & $\begin{array}{l}\text { North-central } \\
\text { plains }\end{array}$ \\
\hline Tornado & 39.8 & 39.3 & 42.6 & 63.0 & 40.5 \\
\hline Severe wind & 31.2 & 48.9 & 41.1 & 52.8 & 44.2 \\
\hline Large hail & 19.0 & 42.2 & 37.6 & 54.8 & 36.3 \\
\hline Any type & 27.0 & 45.7 & 39.6 & 54.7 & 38.6 \\
\hline \multicolumn{6}{|c|}{ 2004-09 cold seasons } \\
\hline Severe weather type & Northeast & Southeast & Midwest & $\begin{array}{c}\text { South-central } \\
\text { plains }\end{array}$ & $\begin{array}{l}\text { North-central } \\
\text { plains }\end{array}$ \\
\hline Tornado & 9.1 & 35.0 & 30.3 & 32.4 & 19.4 \\
\hline Severe wind & 2.7 & 19.8 & 11.8 & 23.1 & 17.5 \\
\hline Large hail & 5.9 & 23.0 & 24.2 & 29.0 & 22.1 \\
\hline Any type & 3.4 & 22.9 & 20.1 & 27.9 & 21.0 \\
\hline
\end{tabular}




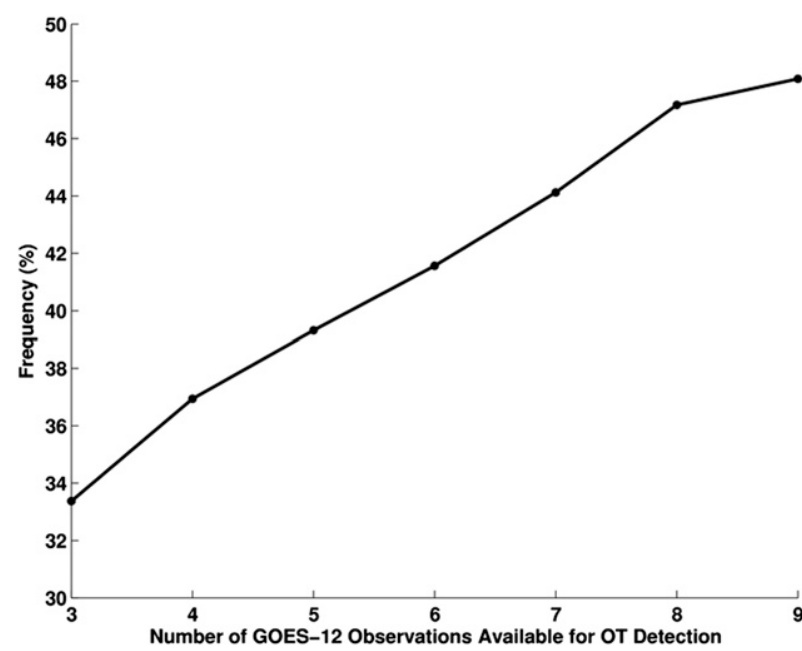

FIG. 9. The relationship between the frequency of OT detections near severe weather events and the number of available GOES scans within the 1-h collocation time period.

radar observations and derived products, severe storm reports from the Storm Prediction Center database, and National Weather Service severe weather warnings. Analysis of radar reflectivity from multiple elevation scans, precipitation echo top, and VIL indicates that the time of an OT detection is well correlated with maxima in these parameters. Reflectivity maximized aloft occurred shortly before or at the time of OT detection and the maximum, then descended to the base reflectivity field shortly after the OT detection. This finding is consistent with the conceptual model of the storm updraft, where hydrometeors are lofted as the updraft intensifies and later descend as the updraft oscillates in intensity.

The mean FAR for warm season OT detections is $\sim 16 \%$ under the assumption that an OT should be associated with at least a $30-\mathrm{dB} Z$ composite reflectivity. The FAR was directly correlated with IRW BT and was as low as $6 \%$ for IRW BTs $\leq 200 \mathrm{~K}$. The cold season results show a similar correlation between IRW BT and FAR, but the FAR for the 210-215-K range is significantly higher. A distinct IRW BT minimum was found to be more often associated with heavy precipitation than a region with a spatially uniform BT.

Despite the 5-9-km GOES-12 spatial resolution and 5-30-min operational scanning frequency over the CONUS, an OT was detected near $42 \%(55 \%)$ of warm season and $22 \%(32 \%)$ of cold season severe weather reports using a $30-\mathrm{km}(60 \mathrm{~km}) \mathrm{OT}-$ severe weather colocation criterion. The fact that OTs are often detected near severe weather highlights the importance of strong penetrating updrafts and the necessity for an objective detection product. All three severe weather types showed comparable OT relationships, with damaging-wind-producing

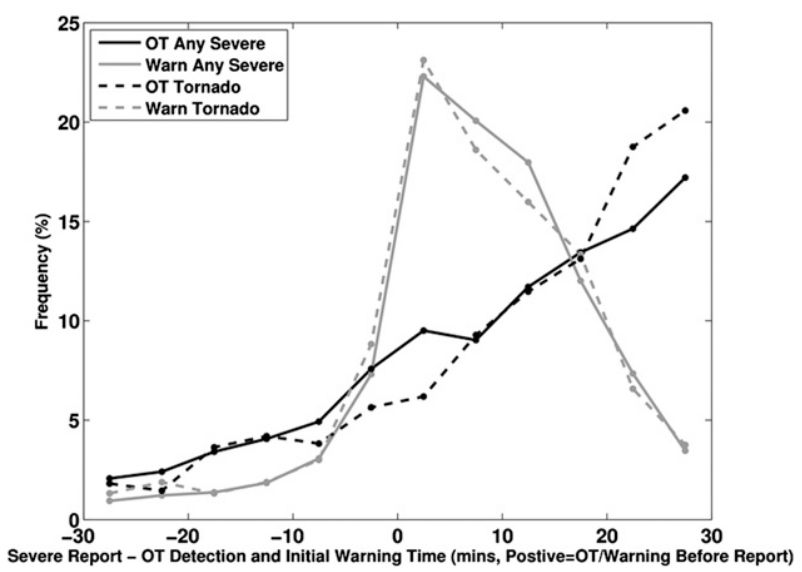

FIG. 10. The time difference between severe weather reports and OT detections (black line) and severe weather reports and NWS severe weather warnings (gray line). Only severe weather warnings with a duration of $30 \mathrm{~min}$ or less are included in this analysis.

storms having the most frequent OT detections during the warm season. The greatest (lowest) percentage of severe weather-OT collocations was found over the south-central plains (northeast United States). Though OTs are not detected as often near severe weather over the northeast and north-central plains regions, when one is detected, it is more likely that the storm is significant. The differences in seasonal severe weather-OT relationships were attributed to a combination of 1) weaker instability present during the cold season, resulting in weaker updrafts and less prominent OT signatures in IRW imagery, and 2) the requirement that an OT be both colder than $215 \mathrm{~K}$ and the tropopause temperature. The OT-severe weather relationship increased by $15 \%$ when GOES operated in rapid-scan mode, showing the importance of high temporal resolution observations for observing and detecting rapidly evolving cloud-top features.

Comparison of the earliest OT detections associated with severe weather reports showed that $75 \%$ occur before severe weather and that $42 \%$ of collocated severe weather reports had either an OT detected before a severe weather warning or no warning issued at all, suggesting that an OT detection could be used to improve situational awareness and increase forecaster confidence that a particular storm is severe, especially in the absence of radar data.

These findings show the potential utility of an objective satellite-based OT detection product in improving forecaster situational awareness and increasing confidence that a storm is severe and/or heavily precipitating near the time when an OT detection is present. The lack of an OT to severe weather collocation may be interpreted as a deficiency in the OT detection methodology, and this is a fair 
conclusion especially with regard to the fixed 215-K IRW BT threshold. One must recognize that 5-30-min GOES data at a 5-9-km spatial resolution over the CONUS are insufficient for objective detection of all OTs, considering an OT can develop and decay multiple times within a $15-\mathrm{min}$ period. Given the $12-\mathrm{K}$ warm bias of 5-9-km GOES relative to $1-2-\mathrm{km}$ MODIS in OT regions, the authors believe that many of the undetected OTs would exhibit IRW BTs colder than $215 \mathrm{~K}$ within 2-km and 30-s to 5-min ABI data and would therefore be detectable. There is also no guarantee that a storm needs to have an OT to produce severe weather, though the literature and the results of this study suggests a positive relationship.

Objective OT and enhanced-V signature detection will be operational products with the GOES-R ABI, which is scheduled to launch in 2016. With the increased temporal and spatial resolutions offered by ABI, improved OT detection capability and possibly increased warning leadtime will be achieved. It is foreseen that this product will have its greatest utility over areas with insufficient radar coverage.

Future work will involve the development of regionally and seasonally dependent OT detection thresholds on a $1^{\circ}$-grid-based analysis of histograms of multiple years of GOES IRW data. Coupled with this will be an analysis of tropopause temperature uncertainty based upon various means of estimating tropopause height (i.e., cold point, potential temperature, and potential vorticity surfaces) from several NWP models. The net result of this analysis will likely improve the detection frequency over the CONUS. The required OT-anvil BT difference may need to be increased to reduce detections of nonsevere elevated cold season convection. Atmospheric instability parameters from an NWP model could be used to eliminate false OT detections in environments where convection is very unlikely to occur. A better understanding of regional OT minimum temperatures and magnitude thresholds for severe storms should be achieved, so that the OT detection algorithm can be more adept at detecting prominent severe weather-producing thunderstorms. In addition, as was done for the composite and base reflectivity maximum echo intensities in this paper, one could analyze a larger sample size of storms with additional radar parameters such as echo top or VIL to investigate the coevolution of these parameters with satellite OT signatures.

Acknowledgments. We thank Lee Cronce (UW-CIMSS), Darryl Herzman (Iowa State University) for technical assistance, and three anonymous reviewers who provided feedback that helped to improve this manuscript. The NEXRAD data provided by NCDC, radar composites by Unidata, severe weather reports provided by SPC, surface elevation maps provided by USGS, the severe warning database provided by Iowa Environmental Mesonet, and GOES-12 data provided by the SSEC Data Center are all greatly appreciated. This research was supported by NASA ROSES Subcontract S09-73322 and NOAA GOES-R Grant NA06NES4400002.

\section{REFERENCES}

Adler, R. F., M. J. Markus, D. D. Fenn, G. Szejwach, and W. E. Shenk, 1983: Thunderstorm top structure observed by aircraft overflights with an infrared radiometer. J. Climate Appl. Meteor., 22, 579-593.

,-- , and -1985 : Detection of severe Midwest thunderstorms using geosynchronous satellite data. Mon. Wea. Rev., 113, 769-781.

Bedka, K., 2011: Overshooting cloud-top detections using MSG SEVIRI infrared brightness temperatures and their relationship to severe weather over Europe. Atmos. Res., 99, 175-189.

_ J. Brunner, R. Dworak, W. Feltz, J. Otkin, and T. Greenwald, 2010: Objective satellite-based detection of overshooting tops using infrared window channel brightness temperature gradients. J. Appl. Meteor. Climatol., 49, 181-201.

— , R. Dworak, J. Brunner, and W. Feltz, 2012: Validation of satellite-based objective overshooting cloud-top detection methods using CloudSat cloud profiling radar observations. J. Appl. Meteor. Climatol., in press.

Brooks, H. E., J. W. Lee, and J. P. Craven, 2003: The spatial distribution of severe thunderstorm and tornado environments from global reanalysis data. Atmos. Res., 67-68, 73-94.

Brunner, J. C., S. A. Ackerman, A. S. Bachmeier, and R. M. Rabin, 2007: A quantitative analysis of the enhanced-V feature in relation to severe weather. Wea. Forecasting, 22, 853-870.

Cecil, D. J., 2009: Passive microwave brightness temperatures as proxies for hailstorms. J. Appl. Meteor. Climatol., 48, 1281-1286.

Davies-Jones, R., 2008: Can a descending rain curtain in a supercell instigate tornadogenesis barotropically? J. Atmos. Sci., 65, 2469-2497.

Dobur, J. C., 2005: A comparison of severe thunderstorm warning verification statistics and population density within the NWS Atlanta county warning area. Preprints, Fourth Annual Southeast Severe Storms Symp., Starkville, MS, East Mississippi Chapter National Weather Association/Amer. Meteor. Soc., D2-6.

Fujita, T. T., 1989: The Teton-Yellowstone tornado of 21 July 1987. Mon. Wea. Rev., 117, 1913-1940.

_ G. S. Forbes, and T. A. Umenhofer, 1976: Close-up view of 20 March 1976 tornadoes: Sinking cloud tops to suction vortices. Weatherwise, 29, 117-131.

Goodman, S. J., and Coauthors, 2005: The North Alabama Lightning Mapping Array: Recent severe storm observations and future prospects. Atmos. Res., 76, 423-437.

Heymsfield, G. M., and R. H. Blackmer Jr., 1988: Satellite-observed characteristics of Midwest severe thunderstorm anvils. Mon. Wea. Rev., 116, 2200-2224.

—, R. Fulton, and J. D. Spinhirne, 1991: Aircraft overflight measurements of Midwest severe storms: Implications on geosynchronous satellite interpretations. Mon. Wea. Rev., 119, 436-455.

Hoinka, K. P., 1999: Temperature, humidity, and wind at the global tropopause. Mon. Wea. Rev., 127, 2248-2265.

Kellenbenz, D. J., T. J. Grafenauer, and J. M. Davies, 2007: The North Dakota tornadic supercells of 18 July 2004: Issues 
concerning high LCL heights and evapotranspiration. Wea. Forecasting, 22, 1200-1213.

Lazzara, M. A., and Coauthors, 1999: The Man computer Interactive Data Access System: 25 years of interactive processing. Bull. Amer. Meteor. Soc., 80, 271-284.

Lemon, L. R., D. W. Burgess, and R. A. Brown, 1978: Tornadic storm airflow and morphology derived from single-Doppler radar measurements. Mon. Wea. Rev., 106, 48-61.

Negri, A. J., 1982: Cloud-top structure of tornadic storms on 10 April 1979 from rapid scan and stereo satellite observations. Bull. Amer. Meteor. Soc., 63, 1151-1159.

—_, and R. F. Adler, 1981: Relation of satellite-based thunderstorm intensity to radar-estimated rainfall. J. Appl. Meteor., 20, 288-300.
Reynolds, D. W., 1980: Observations of damaging hailstorms from geosynchronous satellite digital data. Mon. Wea. Rev., 108, 337-348.

Roberts, R. D., and J. W. Wilson, 1989: A proposed microburst nowcasting procedure using single-Doppler radar. J. Appl. Meteor., 28, 285-303.

Schmit, T. J., M. M. Gunshor, W. P. Menzel, J. J. Gurka, J. Li, and A. S. Bachmeier, 2005: Introducing the next-generation Advanced Baseline Imager on GOES-R. Bull. Amer. Meteor. Soc., 86, 1079-1096.

Srivastava, R. C., 1987: A model of intense downdrafts driven by the melting and evaporation of precipitation. J. Atmos. Sci., 44, 1752-1773. 